\title{
Comprehensive exercise training improves ventilatory muscle function and reduces dyspnea perception in patients with COPD
}

\author{
F. Cortopassi1, A.A.M. Castro1,2, E.F. Porto1,2, M. Colucci1, \\ G. Fonseca1 ${ }^{1}$, L. Torre-Bouscoulet ${ }^{3}$, V. Iamonti ${ }^{1}$, J.R. Jardim ${ }^{1}$
}

\begin{abstract}
Comprehensive exercise training improves ventilatory muscle function and reduces dyspnea perception in patients with COPD. F. Cortopassi, A.A.M. Castro, E.F. Porto, M. Colucci, G. Fonseca, L. Torre-Bouscoulet, V. Iamonti, J.R. Jardim.

Background. Comprehensive exercise training (CET) is an efficient strategy to decrease dyspnea perception in chronic obstructive pulmonary disease (COPD) and may result in significant improvement in ventilatory muscles function. Our aim was to evaluate the effects of general exercise training on dyspnea perception and on respiratory muscles strength in COPD patients.

Methods. Consecutive COPD patients were enrolled to complete a CET programme. The patients underwent a routine that included a global warm up, upper and lower limbs endurance exercise as well as stretching and relaxation. Before and after the CET programme, patients completed maximal inspiratory (PImax) and expiratory (PEmax) pressures measurements, maximal incremental test, endurance test, and 6-min walk distance (6MWD).
\end{abstract}

Results. 71 patients (52 male). Mean age $67.6 \pm 8.6$ years, $\mathrm{FEV}_{1}(\%) 44.2 \pm 16.2$ and Mahler dyspnea scale 6.4 \pm 1.8 . The results before and after the exercise programme were: PImax $64.7 \pm 22.9$ vs. $75.5 \pm 23.7 \mathrm{cmH}_{2} \mathrm{O}$ $(p=0.001)$, PEmax 110.8 \pm 28.1 vs. $120.4 \pm 28.1 \mathrm{cmH}_{2} \mathrm{O}$ $(p=0.004), 6 \mathrm{MWD} 510.6 \pm 90.3$ vs. $528.2 \pm 99.7$ metres $(p=0.88)$, time of incremental test $672 \pm 135$ vs. 856 \pm 226 sec $(p<0.0001)$. Compared with the pre exercise programme, we observed a significant reduction on Borg dyspnea scale $(6.1 \pm 2.8$ to $3.6 \pm 2.3, p<0.0001)$ as well as a longer test time $(504 \pm 218$ to $1.038 \pm 841, p<0.0001)$ at the end of the endurance test after CET programme. Improvement of PImax correlated negatively with dyspnea perception at iso-time during the endurance test $(r=\mathbf{- 0 . 3 3}$, $p=\mathbf{0 . 0 3}$ ).

Conclusions. Our results confirm that CET is associated with significant improvement in PImax, PEmax and provide evidence demonstrating that CET reduces dyspnea perception in patients with COPD.

Monaldi Arch Chest Dis 2009; 71: 3, 106-112.

Keywords: Chronic Obstructive Pulmonary Disease, COPD, Exercise test, Exercise therapy, Rehabilitation, Respiratory muscles.

1 Universidade Federal de Sao Paulo. Escola Paulista de Medicina; Lar Escola Sao Francisco Centro de Reabilitacao Pulmonar, Sao Paulo, Brazil.

2 Adventist University of Sao Paulo; Unasp., Sao Paulo, Brazil.

3 Instituto Nacional de Enfermedades Respiratorias. México.

Correspondence: Felipe Cortopassi, PT, Rua Botucatu, 740-3 Andar, Disciplina de Pneumologia (Respiratory Division), Centro de Reabilitacao Pulmonar Unifesp/Lar Escola Sao Francisco, 04023-062 Sao Paulo, S.P., Brazil; e-mail: fcortopassi@copdnet.org

\section{Introduction}

Patients with Chronic Obstructive Pulmonary Disease (COPD) present dyspnea and deterioration in exercise capacity in association with impaired pulmonary function [1]. Weakness and deconditioning of respiratory and peripheral muscles are currently recognised in these patients as additional factors implicated in the reduction of exercise capacity as well as in quality of life [2]. Maximal voluntary inspiratory (PImax) and expiratory (PEmax) pressures are probably the most frequently reported non-invasive estimates of respiratory muscle force since Black and Hyatt reported this non-invasive technique in 1960s [3].
In COPD patients, inspiratory muscle dysfunction appears to be the result of geometric changes of the thorax, systemic factors and potential structural changes of the inspiratory muscles $[4,5]$. It is probable that inspiratory muscle dysfunction does not limit ventilatory capacity at rest, but it does appear to contribute to dyspnea, decreased exercise capacity and ventilatory failure during exacerbations [6]. Expiratory muscle weakness may lead to problems with speech, and mucus retention due to impaired cough efficacy. These muscles have been found to be recruited in COPD patients both at rest and during loaded breathing [7]. The significance of this activation has not been well-defined. 
Specific inspiratory or expiratory muscle training should not be advised as the sole intervention in COPD, but should be an integrated part of a pulmonary rehabilitation programme whenever dyspnea was caused by respiratory muscle weakness. It has been demonstrated that an increase in strength and endurance of the inspiratory muscles may be observed whenever specific inspiratory muscle training is performed and that this may decrease the patients' dyspnea and increase their performance [8]. However, most of the pulmonary rehabilitation programmes for COPD patients do not include a specific respiratory muscles programme $[9,12]$.

We hypothesise that respiratory muscle strength might be improved with a comprehensive exercise training programme without specific muscle training. The aims of this study were: first, to determine whether a general exercise training programme with non-specific muscle training in patients with severe COPD could result in significant improvement in ventilatory muscle function; and second to evaluate the determinants of improvement in inspiratory muscle function and its association with dyspnea perception.

\section{Methods}

Consecutive patients with COPD were enrolled in an outpatient pulmonary rehabilitation programme between 2001 and 2005. In order to be included in this study patients presented the following selection criteria: (1) moderate-to-severe obstruction $\left(\mathrm{FEV}_{1}<50 \%\right.$ predicted and $\mathrm{FEV}_{1} / \mathrm{FVC}<0.70$ ), according to the criteria of the American Thoracic Society [13] and with a history of cigarette smoking (over 10 pack/years); (2) patients should be clinically stable, with no exacerbations or hospital admissions in the preceding 4 weeks prior to the beginning of the training; their regular treatment was maintained with an optimisation of the bronchodilator therapy; (3) cardiac, musculoskeletal, or neuromuscular disease or any other disease that might interfere with exercise performance were considered as exclusion criteria for this study. Subjects were well motivated to participate in the programme and were currently nonsmokers. The study was approved by the Institutional Ethics Committee and all patients gave their written consent.

Each subject was enrolled in a supervised programme for a total of 90 days distributed in 24 sessions, three times a week. During two weeks before and two weeks after the programme, patients were submitted to pulmonary function test, respiratory muscle function (PImax and PEmax), and exercise capacity (incremental and endurance exercise test on a treadmill and 6-min walk distance [6MWD]).

Exercise programme: Each subject participated in a 24 sessions exercise programme involving supervised exercise three times a week: a) 40 minutes on the treadmill with a load of $80 \%$ of the maximal incremental test; b) 30 minutes of arms exercise with two diagonal movements; c) 20 min- utes of stretching or relaxation. Exercises with diagonal patterns are intended to recruit a large number of the shoulder girdle muscles. The diagonal spiral pattern with a rotary component involves movements in three dimensions with sequential and simultaneous movements of several joints. The first diagonal technique includes flexion-adduction-external rotation of the shoulders motions, while the second diagonal technique includes a flexion-abduction-external rotation motion [14, 15]. Each diagonal exercise lasted two minutes and exercises were carried out alternating the arms. Training was accomplished with a load equivalent to $50 \%$ of the maximal achieved in a maximal incremental upper-limbs test.

\section{Tests}

Spirometry: Spirometric testing (Koko ${ }^{\circledR}, \mathrm{OHD}$ Occupational Health Dynamics Birmingham, AL, USA) was done following ATS/ERS recommendations [16]. Forced vital capacity in litres (FVC), forced expiratory volume in the first second in litres $\left(\mathrm{FEV}_{1}\right)$ and their ratio were measured. The severity of disease was classified according with GOLD stages [17]. Spirometry was repeated after $400 \mathrm{mcg}$ inhaled salbutamol.

Chronic Breathlessness: Dyspnea was assessed with Mahler baseline dyspnea index (BDI), the transitional dyspnea index (TDI) [19] and the modified Borg scale [20].

Maximal incremental test on a treadmill: A maximal incremental symptom-limited test was performed on a treadmill on two succeeding days. The test was performed on a treadmill (Lifestride model 7500, USA) following the Harbor protocol. During the first three minutes patients walked without no inclination on the treadmill at a fixed speed that they felt was comfortable, followed by a $1 \%$ increase in inclination each minute. Heart rate was continuously monitored at the CM5, AVF and V2 leads using electrocardiography (EP-3 Dixtal, Brazil) recordings being taken throughout the exercise and during the recovery period. The lower limbs incremental test was stopped when the oxygen consumption reached the same value as the maximal oxygen consumption reached in the maximal upper limbs incremental test.

Unsupported arm exercise: The exercise consisted of lifting a halter Polypac performing a diagonal movement based on the second diagonal of the proprioceptive neuromuscular facilitation technique [21] over the complete flexion-extension amplitude of the shoulder. This exercise started with the arms crossed in the lap, with the elbows straight and the palms facing down; then the patient lifted the arms up, out and apart until fully extended above the head, approximately $45^{\circ}$ from the vertical, rotating the hand to finish with the palm facing posteriorly; a reverse movement was then done to return to the starting position [21]. The exercise continued alternating the arms till exhaustion. Initial weight was $250 \mathrm{~g}$ which was increased by $250 \mathrm{~g}$ every two minutes. The frequency and rhythm of the movements were imposed by 
a digital metronome (Qwiktime QT-3) programmed to establish 20 repetitions per minute. Patients were encouraged to continue exercising until exhaustion, or occurrence of limiting symptoms (dyspnea and tiredness). The test was halted by the technician when:

1) The patient was observed to be using compensatory thoracic movements to accomplish the exercise;

2) The complete movement amplitude of the shoulder was not being reached; or

3 ) if the patient could no longer follow the metronome frequency.

Six-minute Walk Distance (6 MWD): The maximum distance walked by each patient on a $28-\mathrm{m}$ corridor in 6 minutes was measured. Each subject performed the test twice within a 30-minutes period and the maximum distance was recorded following the ATS recommendations [21].

Table 1. Baseline characteristics of the 71 COPD patients

\begin{tabular}{|c|c|}
\hline Parameter & Value \\
\hline Age (y) & $68(9)$ \\
\hline Male: Female n (\%) & $52(73): 19(27)$ \\
\hline Smoking (pack-years) & $58(32)$ \\
\hline Mahler dyspnea scale (BDI) & $6.4(2.3)$ \\
\hline Mahler dyspnea scale (TDI) & $7.5(2.1)$ \\
\hline Body mass index $\left(\mathrm{Kg} \cdot \mathrm{m}^{-2}\right)$ & $26(5)$ \\
\hline Fat free mass $(\%)$ & $68(11)$ \\
\hline $\mathrm{FEV}_{1}(\mathrm{~L})$ & $1.185(0.510)$ \\
\hline $\mathrm{FEV}_{1}(\%)$ & $44(16)$ \\
\hline $\mathrm{FVC}(\mathrm{L})$ & $2.749(0.760)$ \\
\hline $\mathrm{FVC}(\%)$ & $80(19)$ \\
\hline $\mathrm{FEV}_{1} / \mathrm{FVC}(\%)$ & $52(13)$ \\
\hline $\mathrm{pH}$ & $7.40(0.04)$ \\
\hline $\mathrm{PaO}_{2}(\mathrm{mmHg})$ & $62(7)$ \\
\hline $\mathrm{PaCO}_{2}(\mathrm{mmHg})$ & $42(8)$ \\
\hline $\mathrm{SaO}_{2}(\%)$ & $90(3)$ \\
\hline
\end{tabular}

Values are expressed as mean and standard deviation (SD) or absolute and percentage $(\%)$ values.
Ventilatory Muscle Strength and Endurance: The maximum inspiratory (PImax) and expiratory mouth pressures (PEmax) were measured from functional residual capacity with a standard rigid mouthpiece (Analogical manovacuometer, with an operational interval of -150 to $+150 \mathrm{cmH}_{2} \mathrm{O}$; CriticalMED, Rio de Janeiro, Brazil). Measurements were obtained in the sitting position. To avoid pressure generation by the muscle of the cheeks a small leak was allowed. Five manoeuvers were performed and reproducibility was accepted if the variability between the two best measurements was less than 10 per cent. The best of all efforts was chosen for the analysis.

Statistical Analysis: Data is shown as mean and standard deviation (SD). Comparisons before and after exercise programme were performed using the paired $t$ test. Associations between continuous variables were explored calculating the Pearson's correlation coefficient. The acceptable level of statistical significance for each test was a $p<0.05$. The analysis was performed using the commercial statistics software (Stata, release 9.2, StataCorp, College Station, TX, USA).

\section{Results}

93 patients were initially included. However, 22 of them did not complete the rehabilitation programme: 17 for financial reasons and 5 for acute exacerbation. Finally we analysed the data from 71 patients $(52$ male). The general characteristics of the patients are shown in table 1 . Mean age was $68 \pm 9$ years; $\mathrm{FEV}_{1}$ was $44 \pm 16 \%$ of the predicted; $\mathrm{PaO}_{2}$ was $62 \pm 7 \mathrm{mmHg}, \mathrm{PaCO}_{2} 42 \pm 8 \mathrm{mmHg}$; BDI was $6.4 \pm 2.3$ and TDI $7.5 \pm 2.1$. Fifty two patients (73\%) were classified as COPD GOLD stages 3 or 4 whereas $19(27 \%)$ as stage 1 or 2 .

Table 2 shows the effects of a comprehensive rehabilitation programme on respiratory muscles strength, six minutes walked distance and maximal upper limbs incremental exercise parameters. PImax and PEmax enhanced significantly, $17 \%$ and $9 \%$, respectively $(\mathrm{p}<0.01)$. In respect to the maximal upper limbs incremental test after the rehabilitation programme we found an increase in the max-

Table 2. - Effects of a comprehensive rehabilitation program on the respiratory muscles strength, six minutes walked distance and upper limbs incremental exercise parameters

\begin{tabular}{lccc}
\hline & Pre-rehabilitation & Post-rehabilitation & p value \\
\hline PImax $\left(\mathrm{cmH}_{2} \mathrm{O}\right)$ & $64.7(22.9)$ & $75.5(23.7)$ & $<0.01$ \\
PEmax $\left(\mathrm{cmH}_{2} \mathrm{O}\right)$ & $110.8(28.1)$ & $120.4(28.4)$ & $<0.01$ \\
6 MWD (meters) & $510.6(90.3)$ & $528.2(99.7)$ & 0.82 \\
Upper limbs incremental test & & \\
$\quad$ Borg peak dyspnea & $2.4(1.8)$ & $1.9(1.7)$ & 0.16 \\
$\quad$ Final load $(\mathrm{Kg})$ & $1.3(0.5)$ & $1.7(0.7)$ & $<0.01$ \\
Time $(\mathrm{sec})$ & $378(202)$ & $519(268)$ & $<0.01$ \\
Borg iso-load & $2.4(1.8)$ & $1.5(1.3)$ & $<0.01$ \\
\hline
\end{tabular}

Data are expressed in mean and standard deviation (SD). 
imal load and a decrease in Borg dyspnea (figure 1) at the end of the test and at iso-load. Improvement was seen in all variables in the lower limbs maximal incremental test after the programme, with an increase in 190 meters in the walked distance $(22 \%)(\mathrm{p}<0.005)$ (table 3). Consistently, a decrease in Borg dyspnea score at iso-load and at iso-time was seen in the lower limbs maximal incremental and endurance tests (figure 2).

We found that some variables were associated with the change in PImax (table 4), although significant the strength was weak. We did not find any association of the change in PEmax in relation to pulmonary function, muscle capacity and fat free mass.

\section{Discussion}

The most important findings in our study were: (1) a comprehensive exercise training programme without specific muscle training was found to be associated with a significant improvement of respiratory muscles strength in patients with COPD; (2) the respiratory muscle strength improvement was found to be associated with a decrease in isotime Borg score in incremental and endurance tests; and (3) patients with higher PImax enhancement were those who had higher fat free mass and FVC.

Improvement in respiratory muscle strength after rehabilitation programme has been reported in a previous study by O'Donnell et al [22]. They included 20 moderate to severe COPD patients $\left(\mathrm{FEV}_{1} 41 \pm 3 \%\right)$ in a comprehensive exercise training at high intensity and found that an increase in the ventilatory muscle strength $(29 \pm 11 \%$ in PImax, and $27 \pm 11 \%$ in PEmax), as well as in peripheral muscle strength. However, the improvement was not shown to contribute to the relief of exertional dyspnea or improvement in exercise endurance.

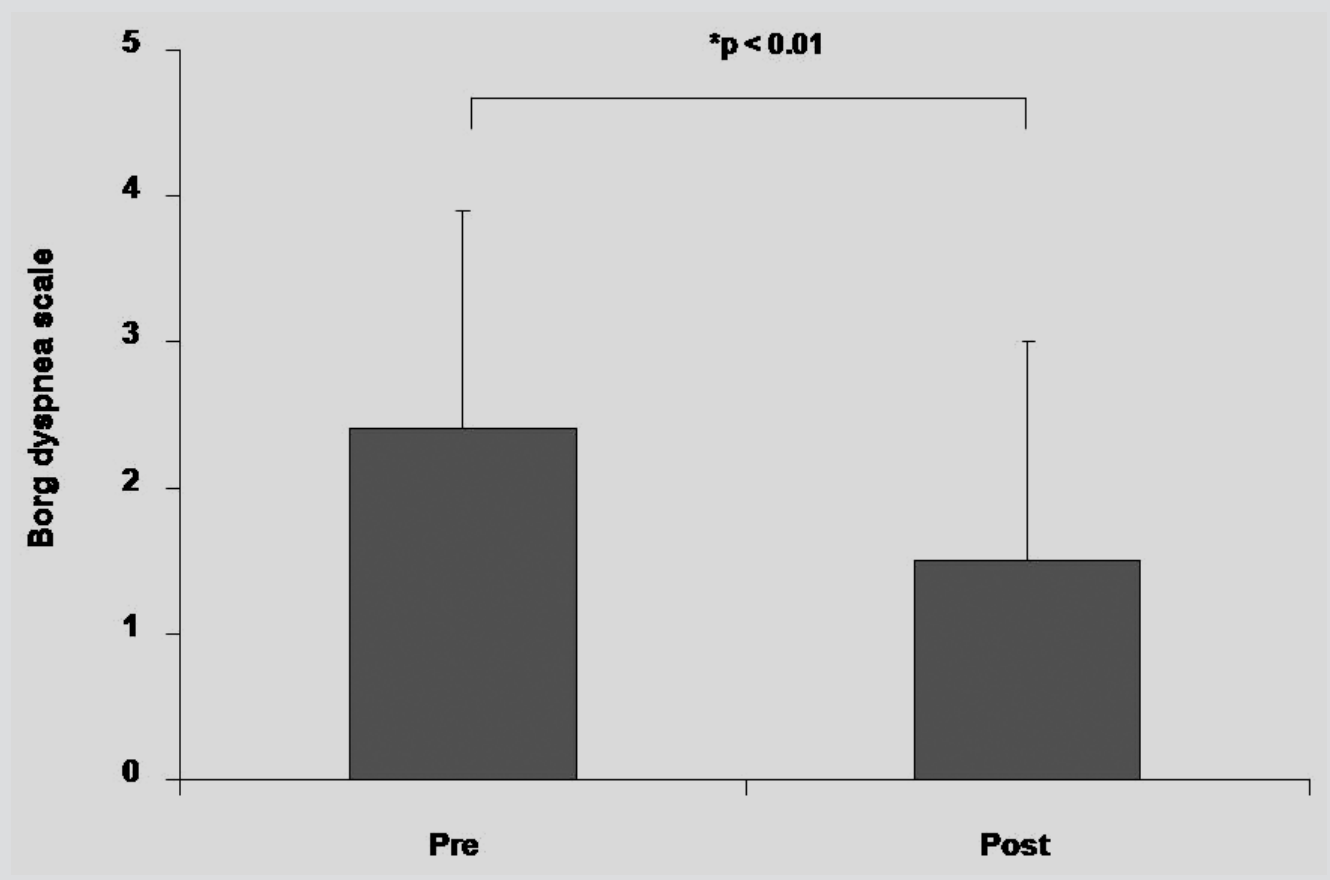

Fig. 1. - Mean and standard deviation of iso-load Borg dyspnea score for the upper limbs incremental test pre and post a comprehensive exercise programme. * Paired $t$ test.

Table 3. - Effects of a comprehensive training program on the lower limbs exercise parameters in COPD patients

\begin{tabular}{cccc}
\hline Incremental Test & Pre-rehabilitation & Post-rehabilitation & p value \\
\hline Time (sec) & $672(135)$ & $856(226)$ & $<0.01$ \\
Distance (meters) & $0.86(0.30)$ & $1.05(0.38)$ & $<0.01$ \\
Borg peak dyspnea & $6.9(2.7)$ & $6.6(3.0)$ & 1 \\
Borg iso-load & $6.9(2.7)$ & $5.0(2.9)$ & $<0.01$ \\
Endurance Test & & & \\
Time (sec) & $504(218)$ & $1038(841)$ & $<0.01$ \\
Borg peak dyspnea & $6.1(2.8)$ & $5.6(3.0)$ & 0.23 \\
Borg isotime & $6.1(2.8)$ & $3.6(2.3)$ & $<0.01$ \\
\hline
\end{tabular}

Data are expressed in mean and standard deviation (SD). 


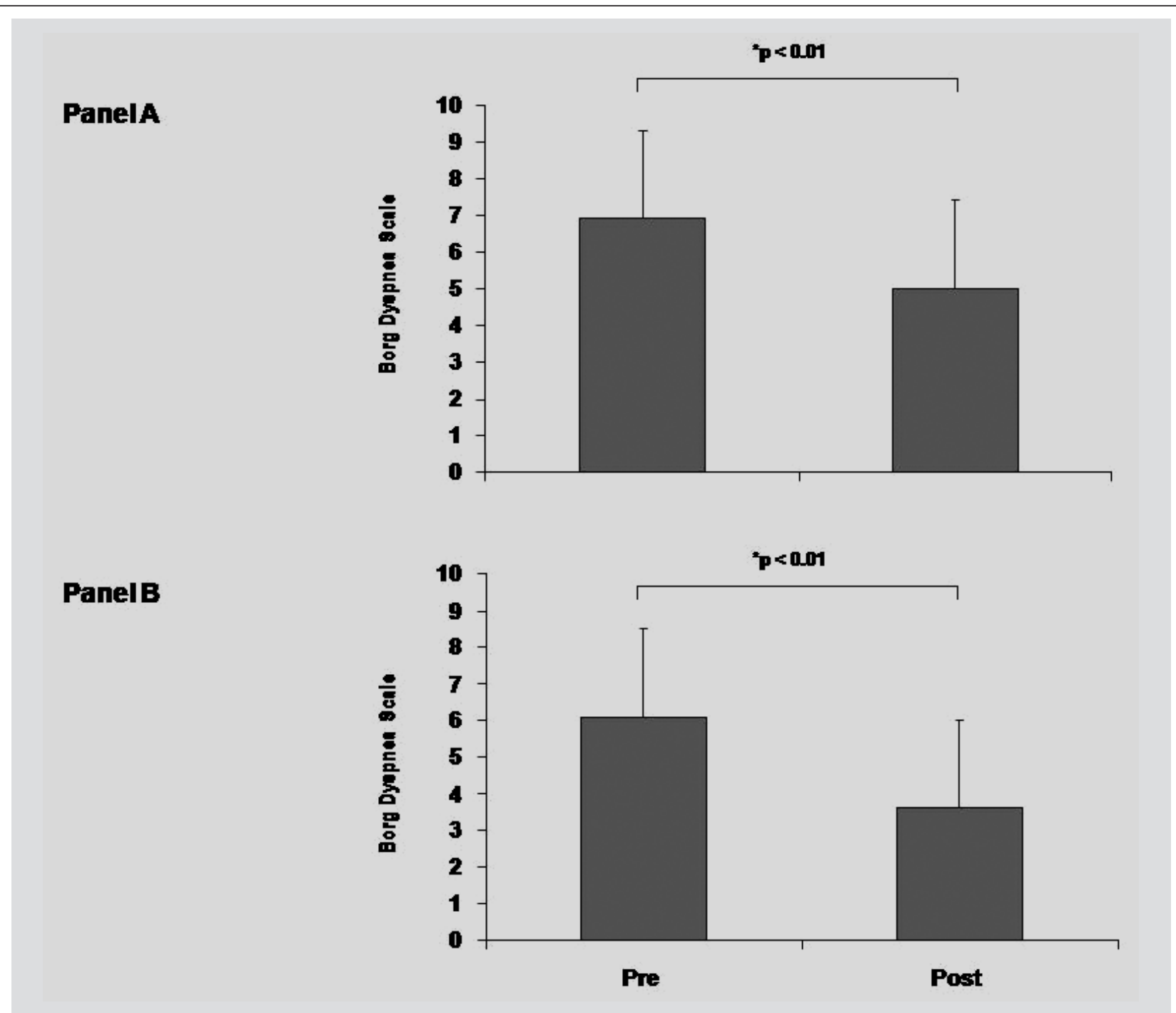

Fig. 2. - Mean and standard deviation of iso-load Borg dyspnea scale for the lower limbs incremental test (Panel A) and iso-time Borg dyspnea scale for the lower limbs endurance test (Panel B) pre and post a comprehensive exercise programme. * Paired $t$ test.

Table 4. - Variables associated with the increase in PImax

\begin{tabular}{lcc}
\hline & \multicolumn{2}{c}{ PImax } \\
\cline { 2 - 3 } & $\mathrm{r}$ & $\mathrm{p}$ value \\
\hline Fat free mass (\%) & 0.29 & 0.03 \\
FVC (\%) & 0.34 & 0.01 \\
FVC (L) & 0.29 & 0.03 \\
Endurance Borg iso-time (lower limbs) & -0.33 & 0.03 \\
Borg incremental test in lower limbs before rehabilitation & -0.30 & 0.02 \\
\hline
\end{tabular}

$\mathrm{r}=$ Pearson's Correlation Coefficient.

Contrary to O'Donnell et al findings we found that the Borg dyspnea perception at iso-time and isoload during a lower limbs maximal and endurance tests decreased after a rehabilitation programme and similar result was found in the incremental test for upper limbs $(p<0.01)$. It is currently acknowledged that pulmonary rehabilitation is an important therapy in the management of patients with symptomatic COPD as it improves the perception of dyspnea, exercise tolerance and health-related quality of life. We observed an improvement of BDI/TDI index (table 1), which may be considered a direct effect of exercise training in accordance with other studies [11]. The current Pulmonary Rehabilitation Evidence-Based Clinical Practice Guidelines [23] states that the combinedtraining of both lower and upper limbs may reduce Borg score for perceived dyspnea. We are not as- 
suming that respiratory muscle strength was responsible for the dyspnea reduction since our patients were also submitted to arms and legs exercises. However, it might be that the respiratory muscles played a secondary role in the reduction in breathlessness of our patients. Gosselink et al have showed that ventilatory muscles impairment may be a limiting factor in exercise in COPD patients [24]; in addition O'Donnell et al have seen that an increase in the ventilatory muscles strength and endurance may increase the effort capacity in COPD patients [22]. The study by Holland et al [25] compared arm training combined with lower limb training vs lower limb training alone in 38 COPD patients. They found in the combined-training group a significant improvement in arm endurance $(p=0.02)$ and a trend toward reduced Borg scale for dyspnea $(p=0.07)$.

To the best of our knowledge, this is the first study demonstrating that the combined-training (unsupported training for upper limbs and endurance training by treadmill for lower limbs) decreases dyspnea. Geddes et al [26] found that aerobic exercise training alone does not improve ventilatory muscle strength and endurance but we attributed these negative results to the lower intensity of the training load. In our group, however, the exercise training was performed with a high intensity workload $(80 \%)$ which may explain the significant improvement in the ventilatory muscle of our patients.

It is well known that COPD patients present changes in muscle fibre type, reduced capillarity, decreased oxidative enzyme, nutrition depletion, and steroids use $[27,28]$. Together, they can potentially explain the reduction in muscle endurance. Weight loss and muscle wasting have long been considered events that highlight progression of COPD. Although investigators have been trying to show the effects of caloric and anabolic interventions during pulmonary rehabilitation [29-31] exercise could be the first option in stable patients to increase muscle mass and better exercise endurance [32]. In the present study, PImax improvement was found to be associated with the a higher baseline fat free mass. This improvement was seen even when the baseline pre rehabilitation PImax was normal what suggests that patients with no respiratory muscle weakness and submitted to an exercise programme may gain an extra respiratory muscle strength.

Although we have not seen an improvement in the 6MWD in our patients after the rehabilitation programme, exercise tolerance during the 6-min walk distance in patients with COPD has been demonstrated. Benstrup et al demonstrated in 32 COPD outpatient-based submitted to pulmonary rehabilitation an increase of 113 meters during the 6MWD [33]. Wedzicha et al found a similar increase in their group of patients (191 to 279 meters) after pulmonary rehabilitation [34]. Although the reason our finding is unclear, we believe that the high pre rehabilitation distance in the $6 \mathrm{~min}-$ walking test ( $510 \pm 90$ meters) could have abolished an overall effect of the programme in this particu- lar parameter as there was a significant increase in the endurance and in the incremental leg exercise test. The long distance walked by our patients, even before the programme completion, has been previously recognized by our group [35] and it might be secondary to the kind of daily life activities COPD patients of developing countries usually have; for instance as most of them do not have their own transportation they have to walk long distance in a daily basis.

Our study has a limitation; although our study was not a randomized control trial, the results were consistent with previous randomised controlled groups [34, 36]. It has been convincingly demonstrated that pulmonary rehabilitation is beneficial to COPD patients and currently it is considered that there is sufficient evidence to prove that it may be considered unethical by some not to ensure patient exercise during a control period.

In conclusion, our results provide evidence supporting that comprehensive exercise training is a useful strategy to decrease dyspnea perception in patients with COPD and also to improve respiratory muscle strength without any specific training. The reduction in iso-load dyspnea was associated to baseline fat free mass.

Acknowledgements: The authors would like to thank all the multiprofessional team from the Pulmonary Rehabilitation Centre - Lar Escola Sao Francisco-Unifesp-EPM.

\section{References}

1. Killian KJ, Leblanc P, Martin DH, Summers E, Jones NL, Campbell EJ. Exercise capacity and ventilatory, circulatory, and symptom limitation in patients with chronic airflow limitation. Am Rev Respir Dis 1992; 146: 935-40.

2. Hamilton AL, Killian KJ, Summers E, Jones NL. Muscle strength, symptom intensity, and exercise capacity in patients with cardiorespiratory disorders. Am J Respir Crit Care Med 1995; 152 (6 Pt 1): 2021-31.

3. Black LF, Hyatt RE. Maximal respiratory pressures: normal values and relationship to age and sex. Am Rev Respir Dis 1969; 99: 696-702.

4. Skeletal muscle dysfunction in chronic obstructive pulmonary disease. A statement of the American Thoracic Society and European Respiratory Society. Am J Respir Crit Care Med 1999; 159 (4 Pt 2): S1-40.

5. Arora NS, Rochester DF. COPD and human diaphragm muscle dimensions. Chest 1987; 91: 719-24.

6. Begin P, Grassino A. Inspiratory muscle dysfunction and chronic hypercapnia in chronic obstructive pulmonary disease. Am Rev Respir Dis 1991; 143 (5 Pt 1): 905-12.

7. Ninane V, Rypens F, Yernault JC, De Troyer A. Abdominal muscle use during breathing in patients with chronic airflow obstruction. Am Rev Respir Dis 1992; 146: 16-21.

8. Lotters F, van Tol B, Kwakkel G, Gosselink R. Effects of controlled inspiratory muscle training in patients with COPD: a meta-analysis. Eur Respir J 2002; 20: 570-6.

9. Nici L, Donner C, Wouters E, et al. American Thoracic Society/European Respiratory Society statement on pulmonary rehabilitation. Am J Respir Crit Care Med 2006 15; 173: 1390-413. 
10. Weiner P, Magadle R, Berar-Yanay N, Davidovich A, Weiner M. The cumulative effect of long-acting bronchodilators, exercise, and inspiratory muscle training on the perception of dyspnea in patients with advanced COPD. Chest 2000; 118: 672-8.

11. Pulmonary rehabilitation: joint ACCP/AACVPR evidence-based guidelines. ACCP/AACVPR Pulmonary Rehabilitation Guidelines Panel. American College of Chest Physicians. American Association of Cardiovascular and Pulmonary Rehabilitation. Chest 1997 5; 112: 1363-96.

12. Leith DE, Bradley M. Ventilatory muscle strength and endurance training. $J$ Appl Physiol 1976; 41: 508-16.

13. Standards for the diagnosis and care of patients with chronic obstructive pulmonary disease. American Thoracic Society. Am J Respir Crit Care Med 1995; 152 (5 Pt 2): S77-121.

14. Porto EF, Castro AA, Nascimento O, Oliveira RC, Cardoso F, Jardim JR. Modulation of operational lung volumes with the use of salbutamol in COPD patients accomplishing upper limbs exercise tests. Respir Med 2009; 103: 251-7.

15. Surburg PR, Schrader JW. Proprioceptive Neuromuscular Facilitation Techniques in Sports Medicine: A Reassessment. J Athl Train 1997; 32: 34-9.

16. Miller MR, Hankinson J, Brusasco V, et al. Standardisation of spirometry. Eur Respir J 2005; 26: 319-38.

17. Pauwels RA, Buist AS, Calverley PM, Jenkins CR, Hurd SS. Global strategy for the diagnosis, management, and prevention of chronic obstructive pulmonary disease. NHLBI/WHO Global Initiative for Chronic Obstructive Lung Disease (GOLD) Workshop summary. Am J Respir Crit Care Med 2001; 163: 1256-76.

18. Mahler DA, Weinberg DH, Wells CK, Feinstein AR. The measurement of dyspnea. Contents, interobserver agreement, and physiologic correlates of two new clinical indexes. Chest 1984; 85: 751-8.

19. Borg GA. Psychophysical bases of perceived exertion. Med Sci Sports Exerc 1982; 14: 377-81.

20. Porto EF, Castro AA, Velloso M, Nascimento O, Dal Maso F, Jardim JR. Exercises using the upper limbs hyperinflate COPD patients more than exercises using the lower limbs at the same metabolic demand. Monaldi Arch Chest Dis 2009; 71: 21-6.

21. ATS statement: guidelines for the six-minute walk test. Am J Respir Crit Care Med 2002 1; 166: 111-7.

22. O’Donnell DE, McGuire M, Samis L, Webb KA. General exercise training improves ventilatory and peripheral muscle strength and endurance in chronic airflow limitation. Am J Respir Crit Care Med 1998; 157 (5 Pt 1): 1489-97.

23. Ries AL, Bauldoff GS, Carlin BW, et al. Pulmonary Rehabilitation: Joint ACCP/AACVPR Evidence-Based Clinical Practice Guidelines. Chest 2007 May; 131 (5 Suppl): 4S-42S.
24. Gosselink R, Troosters T, Decramer M. Peripheral muscle weakness contributes to exercise limitation in COPD. Am J Respir Crit Care Med 1996; 153: 976-80.

25. Holland AE, Hill CJ, Nehez E, Ntoumenopoulos G. Does unsupported upper limb exercise training improve symptoms and quality of life for patients with chronic obstructive pulmonary disease? J Cardiopulm Rehabil 2004; 24: 422-7.

26. Geddes EL OBK, Brooks D, Reid WD, Crowe J. Does aerobic exercise training improve inspiratory muscle function in individuals with Chronic Obstructive Pulmonary Disease? A systematic review. Cardiopulmonary Phys Ther J 2007; 18: 3-13.

27. Allaire J, Maltais F, Doyon JF, et al. Peripheral muscle endurance and the oxidative profile of the quadriceps in patients with COPD. Thorax 2004; 59: 673-8.

28. Gea JG, Pasto M, Carmona MA, Orozco-Levi M, Palomeque J, Broquetas J. Metabolic characteristics of the deltoid muscle in patients with chronic obstructive pulmonary disease. Eur Respir J 2001; 17: 939-45.

29. Creutzberg EC, Wouters EF, Mostert R, Pluymers RJ, Schols AM. A role for anabolic steroids in the rehabilitation of patients with COPD? A double-blind, placebocontrolled, randomized trial. Chest 2003; 124: 1733-42.

30. Schols AM, Slangen J, Volovics L, Wouters EF. Weight loss is a reversible factor in the prognosis of chronic obstructive pulmonary disease. Am J Respir Crit Care Med 1998; 157 (6 Pt 1): 1791-7.

31. Ferreira IM, Verreschi IT, Nery LE, et al. The influence of 6 months of oral anabolic steroids on body mass and respiratory muscles in undernourished COPD patients. Chest 1998; 114: 19-28.

32. Franssen FM, Broekhuizen R, Janssen PP, Wouters EF, Schols AM. Effects of whole-body exercise training on body composition and functional capacity in normalweight patients with COPD. Chest 2004; 125: 2021-8.

33. Bendstrup KE, Ingemann Jensen J, Holm S, Bengtsson B. Out-patient rehabilitation improves activities of daily living, quality of life and exercise tolerance in chronic obstructive pulmonary disease. Eur Respir J 1997; 10: 2801-6.

34. Wedzicha JA, Bestall JC, Garrod R, Garnham R, Paul EA, Jones PW. Randomized controlled trial of pulmonary rehabilitation in severe chronic obstructive pulmonary disease patients, stratified with the MRC dyspnoea scale. Eur Respir J 1998; 12: 363-9.

35. Cardoso F, Tufanin AT, Colucci M, Nascimento O, Jardim JR. Replacement of the 6-min walk test with maximal oxygen consumption in the BODE Index applied to patients with COPD: an equivalency study. Chest 2007; 132: 477-82.

36. Goldstein RS, Gort EH, Stubbing D, Avendano MA, Guyatt GH. Randomised controlled trial of respiratory rehabilitation. Lancet 1994; 19; 344 (8934): 1394-7.

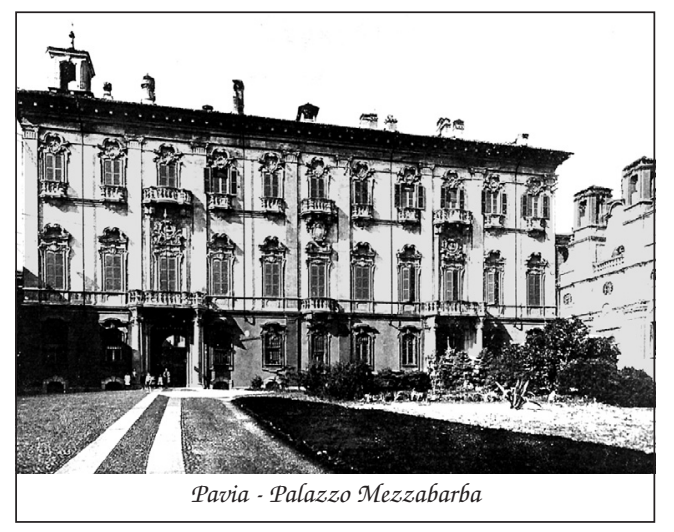

